BMC

Microbiology
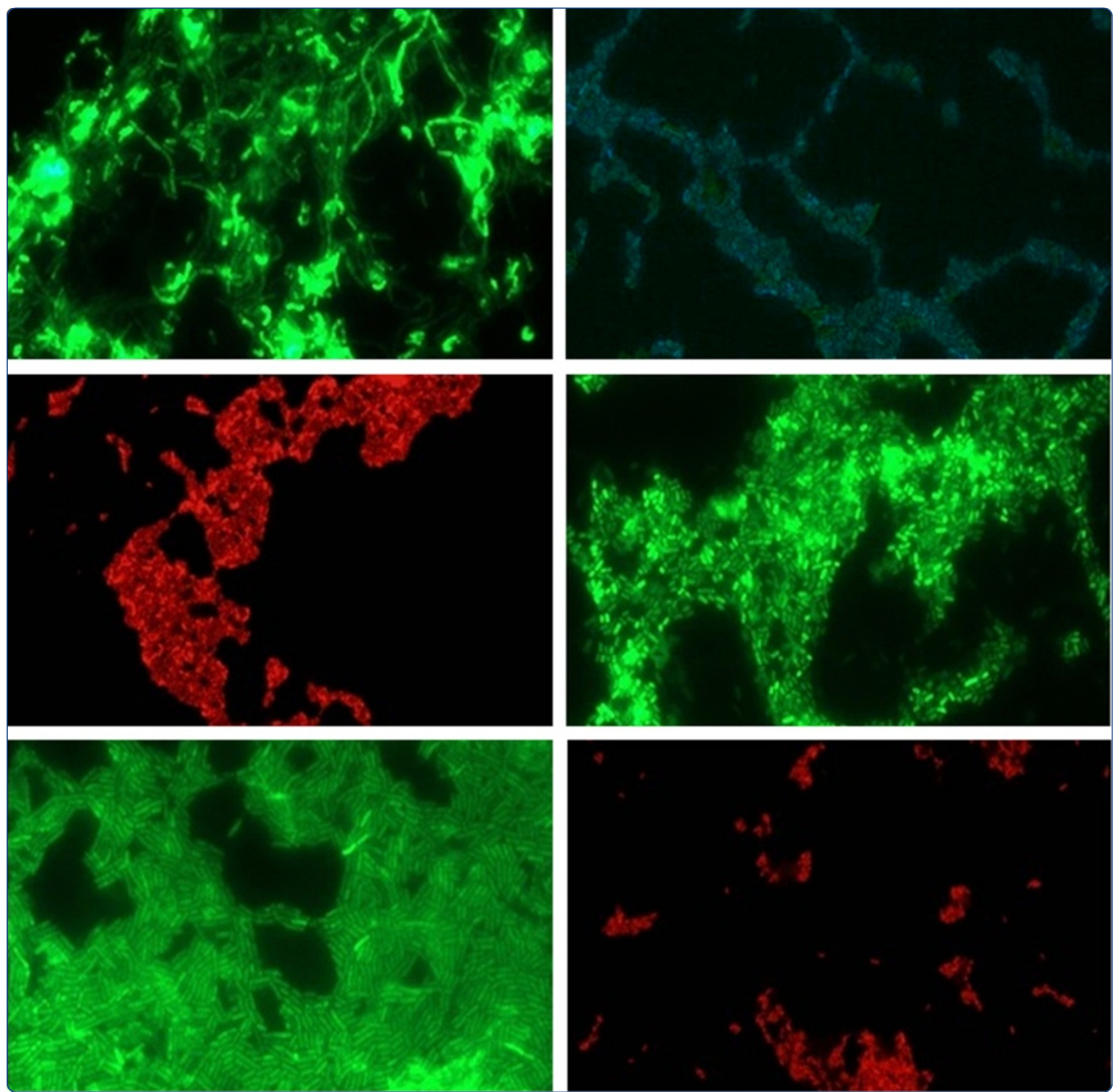

Fluorescence in situ Hybridization method using Peptide Nucleic Acid probes for rapid detection of Lactobacillus and Gardnerella spp.

Machado et al. 


\title{
Fluorescence in situ Hybridization method using Peptide Nucleic Acid probes for rapid detection of Lactobacillus and Gardnerella spp.
}

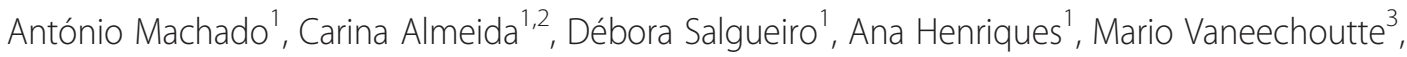 \\ Freddy Haesebrouck ${ }^{4}$, Maria João Vieira', Ligia Rodrigues ${ }^{1}$, Nuno Filipe Azevedo ${ }^{2}$ and Nuno Cerca ${ }^{1 *}$
}

\begin{abstract}
Background: Bacterial vaginosis (BV) is a common vaginal infection occurring in women of reproductive age. It is widely accepted that the microbial switch from normal microflora to BV is characterized by a decrease in vaginal colonization by Lactobacillus species together with an increase of Gardnerella vaginalis and other anaerobes. Our goal was to develop and optimize a novel Peptide Nucleic Acid (PNA) Fluorescence in situ Hybridization assay (PNA FISH) for the detection of Lactobacillus spp. and G. vaginalis in mixed samples.
\end{abstract}

Results: Therefore, we evaluated and validated two specific PNA probes by using 36 representative Lactobacillus strains, 22 representative $G$. vaginalis strains and 27 other taxonomically related or pathogenic bacterial strains commonly found in vaginal samples. The probes were also tested at different concentrations of $G$. vaginalis and Lactobacillus species in vitro, in the presence of a HeLa cell line. Specificity and sensitivity of the PNA probes were found to be $98.0 \%$ (95\% confidence interval (Cl), from 87.8 to 99.9\%) and 100\% (95\% Cl, from 88.0 to 100.0\%), for Lactobacillus spp.; and 100\% (95\% Cl, from 92.8 to 100\%) and 100\% (95\% Cl, from 81.5 to 100.0\%) for G. vaginalis. Moreover, the probes were evaluated in mixed samples mimicking women with BV or normal vaginal microflora, demonstrating efficiency and applicability of our PNA FISH.

Conclusions: This quick method accurately detects Lactobacillus spp. and G. vaginalis species in mixed samples, thus enabling efficient evaluation of the two bacterial groups, most frequently encountered in the vagina.

Keywords: Fluorescence in situ Hybridization (FISH), Peptide Nucleic Acid Probe (PNA probe), Lactobacillus spp., Gardnerella vaginalis, Bacterial vaginosis

\section{Background}

Bacterial vaginosis (BV) is worldwide the most important perturbation of the normal vaginal condition in women [1]. BV affects pregnant women or women in reproductive age leading to high public health costs and associated complications, such as pelvic inflammatory disease, preterm birth, postoperative infections and an increased risk of acquisition and transmission of sexually transmitted diseases, such as human immunodeficiency virus (HIV) and human papillomavirus (HPV) [1,2]. Several studies have associated this condition with an imbalance in the vaginal microflora

\footnotetext{
* Correspondence: nunocerca@ceb.uminho.pt

'IBB - Institute for Biotechnology and Bioengineering, Centre of Biological Engineering, University of Minho, Campus de Gualtar, Braga 4710-057, Portugal

Full list of author information is available at the end of the article
}

although BV etiology is still unclear [3-5]. BV has been described as a complex interaction of multiple factors related with several components of the vaginal microbial ecosystem and their human host, although many of these factors remain uncharacterized $[2,6]$. When $\mathrm{BV}$ is established, a decrease in the beneficial bacteria number, specifically Lactobacillus spp., and an increase in the numbers of anaerobic bacteria, such as Gardnerella vaginalis, Atopobium vaginae and Mobiluncus spp., are observed in the vaginal epithelium $[7,8]$. The disruption of the normal microflora and overgrowth by anaerobes are responsible for the BV signs and symptoms, namely the increase in vaginal $\mathrm{pH}$ $(\mathrm{pH} \geq 4.5)$, the formation of vaginal biofilms on vaginal epithelia, observable as clue cells [9], fishy odor and milky vaginal discharge in the absence of an inflammatory

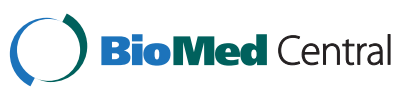


response $[9,10]$. Although $\mathrm{BV}$ is often considered a polymicrobial condition, the predominant bacterial species identified is G. vaginalis [2]. In 2005, Swidsinski and colleagues characterized clinical vaginal swabs and found that a multispecies biofilm was formed, which was mainly composed of G. vaginalis and Atopobium vaginae. They hypothesized that $G$. vaginalis is the initial colonizing species and that its adherence is required before other BVassociated anaerobes are able to interact with the vaginal epithelium [10]. Due to G. vaginalis resistance against Lactobacillus spp. antimicrobial products, such as hydrogen peroxide and lactic acid [11,12], biofilm forming G. vaginalis might compete in initial adhesion against Lactobacillus spp. and may enable other anaerobes to incorporate and grow inside the biofilm [13]. Therefore, the development of an optimized and rapid diagnostic tool that allows the simultaneous visualization of G. vaginalis increase and Lactobacillus species reduction in vaginal samples could be of great use for further study of the previous hypothesis and as a diagnostic tool.

Fluorescence in situ Hybridization (FISH) is a molecular method used to identify and quantify microorganisms in a wide range of samples. This technique combines the simplicity of microscopic observation and the specificity of DNA/rRNA hybridization, allowing detection of selected bacterial species and morphologic visualization $[14,15]$. Nowadays, Peptide Nucleic Acid (PNA) probes are used instead of natural nucleic acids to improve FISH efficiency [16-19], because they enable more rapid and more specific hybridization [19-23]. The main goal of our work was to evaluate the PNA-FISH performance on mixed samples using a multiplex approach to detect Lactobacillus spp. and G. vaginalis. To validate the PNA probes, we determined, both in silico and in vitro, their specificity and sensitivity, using a broad diversity of representative Lactobacillus and Gardnerella strains, as well as other taxonomically related or pathogenic bacterial strains commonly found in vaginal samples. To confirm the usefulness of our methodology, the efficiency and specificity of the probes was also tested at different concentrations of Lactobacillus and G. vaginalis strains in the presence of a monolayer of HeLa cells.

\section{Methods}

\section{Culture of bacterial strains}

The bacterial strains used in this study are listed in Table 1. All strains from Lactobacillus spp. were grown in Man, Rogosa and Sharpe agar (MRS; Sigma, Portugal), excepting L. iners that was grown in Brucella Blood agar (BBA; Oxoid, United Kingdom) as well as Atopobium vaginae and Gardnerella vaginalis. The remaining bacterial species were cultured on Brain Heart Infusion agar (BHI; Oxoid, United Kingdom) or Trypticase Soy Agar (TSA; Oxoid, United Kingdom). Each bacterial culture was streaked onto fresh plates every $48-72 \mathrm{~h}$. Plates were incubated at $37^{\circ} \mathrm{C}$ or $30^{\circ} \mathrm{C}$ (in the case of L. pentosus strains) under anaerobic conditions (AnaeroGen Atmosphere Generation system; Oxoid, United Kingdom) for $24-48 \mathrm{~h}$ prior to FISH experiments.

\section{PNA probe design}

To identify Gardnerella genus potential oligonucleotidestarget for the probe design, we used the software Primrose [24], coupled with the 16S rRNA databases from the Ribosomal Database Project II (version 10.0; http://rdp.cme. msu.edu/) [25]. Complementarity with a low number of non-target and a high number of target sequences, as well as a higher predicted melting temperature and the absence of self-complementary sequences, were the main criteria for the PNA probe design. The selected sequences were synthesized (Panagene, Daejeon, South Korea) and the oligonucleotides $\mathrm{N}$ terminus was attached to an Alexa Fluor 594 molecule via a double 8-amino-3,6-dioxaoctanoic acid (AEEA) linker (PNA Probe: Gard162, Alexa Fluor 594OO-CAGCATTACCACCCG; HPLC purified > 90\%). The Gard162 probe hybridizes between positions 162 and 176 of the G. vaginalis strain 409-05 16S rRNA sequence (RDPII ID: S001872672) and was selected for probe design. For the detection of Lactobacillus spp. a previously developed probe [26], Lac663 was selected. This probe was attached to an Alexa Fluor 488 molecule, also via an AEEA linker (PNA Probe: Lac663, Alexa Fluor 488OO-ACATGGAGTTCCACT; HPLC purified > 90\%).

\section{In silico determination of sensitivity and specificity}

Theoretical specificity and sensitivity were calculated according to Almeida et al. [27]. Briefly, the theoretical specificity and sensitivity of both probes were evaluated using updated databases available at the Ribosomal Database Project II (RDP II; http://rdp.cme.msu.edu/) through the Primrose software, and then were confirmed by a BLAST search at the National Centre for Biotechnology Information (http://www.ncbi.nlm.nih.gov/BLAST/; see Table 2). Only target sequences with at least 1200 base pairs and good quality were included. Briefly, theoretical sensitivity was calculated as $t s /(T t s) \times 100$, where $t s$ stands for the number of target strains detected by the probe and Tts for the total number of target strains present in the RDP II database (http://rdp.cme.msu.edu/probematch/, last accession date, May 2012). Theoretical specificity was calculated as nts/ $(T n t) \times 100$, where $n t s$ stands for the number of non-target strains that did not react with the probe and Tnt for the total of non-target strains examined.

\section{FISH hybridization procedure}

Biomass from a single colony of each strain was diluted and homogenised in sterile water, and then $20 \mu \mathrm{L}$ were 
Table 1 Bacterial strains used in PNA-FISH assays and their specificity with Lac663 and Gard162 probes

\begin{tabular}{|c|c|c|c|}
\hline Bacterial species & Collection strain & Lac663 Probe efficiency & Gard162 Probe efficiency \\
\hline Lactobacillus acidophilus & ATCC $4356^{\top}$ & ++++ & - \\
\hline L. crispatus & ATCC $33820^{\top}$ & ++++ & - \\
\hline L. gasseri & ATCC $9857^{\top}$ & ++++ & - \\
\hline L. reuteri & NCFB $2656^{\top}$ & +++ & - \\
\hline L. rhamnosus & ATCC $7469^{\top}$ & ++++ & - \\
\hline L. rhamnosus & CECT $288^{\top}$ & ++++ & - \\
\hline L. johnsonii & ATCC $11506^{\top}$ & ++++ & - \\
\hline L. hilgardii & NCFB $962^{\top}$ & +++ & - \\
\hline L. delbrueckii subsp. delbrueckii & ATCC $9649^{\top}$ & +++ & - \\
\hline L. delbrueckii subsp. lactis & ATCC $12315^{\top}$ & +++ & - \\
\hline L. pentosus & CECT $4023^{\top}$ & ++++ & - \\
\hline L. casei & CECT $5275^{\top}$ & ++++ & - \\
\hline L. coryniformis subsp. torquens & CECT $4129^{\top}$ & ++++ & - \\
\hline L. paracasei & CECT $227^{\top}$ & ++++ & - \\
\hline L. agilis & CCUG $31450^{\top}$ & ++++ & - \\
\hline L. animalis & ATCC $35046^{\top}$ & +++ & - \\
\hline L. bifermentans & ATCC $35409^{\top}$ & +++ & - \\
\hline L. brevis & ATCC $14869^{\top}$ & ++++ & - \\
\hline L. buchneri & ATCC $4005^{\top}$ & +++ & - \\
\hline L. fermentum & ATCC $11739^{\top}$ & +++ & - \\
\hline L. curvatus subsp. curvatus & ATCC $25601^{\top}$ & ++++ & - \\
\hline L. farciminis & DSM 20182T & ++++ & - \\
\hline L. fructivorans & ATCC $8288^{\top}$ & +++ & - \\
\hline L. gallinarum & CCUG $31412^{\top}$ & ++++ & - \\
\hline L. graminis & DSM $20719^{\top}$ & ++ & - \\
\hline L. hamsteri & ATCC $43851^{\top}$ & +++ & - \\
\hline L. helveticus & ATCC $15009^{\top}$ & ++++ & - \\
\hline L. intestinalis & ATCC $49335^{\top}$ & +++ & - \\
\hline L. murinus & ATCC $35020^{\top}$ & ++++ & - \\
\hline L. parabuchneri & ATCC $12936^{\top}$ & ++++ & - \\
\hline L. paracasei subsp. paracasei & CCUG $27320^{\top}$ & +++ & - \\
\hline L. plantarum & NCIMB $8827^{\top}$ & +++ & - \\
\hline L. ruminis & ATCC $27781^{\top}$ & ++++ & - \\
\hline L. sakei subsp. carnosus & CCUG $8045^{\top}$ & ++ & - \\
\hline L. salivarius & DEVRIESE 94/438 & +++ & - \\
\hline L. plantarum & NCCB $46043^{\top}$ & +++ & - \\
\hline L. lactis 53 & - & - & - \\
\hline Streptococcus. thermophilus A & - & - & - \\
\hline S. thermophilus B & - & +++ & - \\
\hline Leuconostoc mesenteroides & - & - & - \\
\hline Bacillus subtilis & DSM 7-10 & - & - \\
\hline Enterococcus faecium & CECT $410^{\top}$ & - & - \\
\hline E. faecalis & CECT $184^{\top}$ & - & - \\
\hline Gardnerella vaginalis 5-1 & - & - & ++++ \\
\hline G. vaginalis 101 & - & - & ++++ \\
\hline G. vaginalis $A M D$ & - & - & ++++ \\
\hline G. vaginalis & ATCC & - & ++++ \\
\hline
\end{tabular}


Table 1 Bacterial strains used in PNA-FISH assays and their specificity with Lac663 and Gard162 probes (Continued)

\begin{tabular}{|c|c|c|c|}
\hline G. vaginalis & Belgian isolate 1 & - & +++ \\
\hline G. vaginalis & Belgian isolate 2 & - & ++++ \\
\hline G. vaginalis & Belgian isolate 3 & - & ++++ \\
\hline G. vaginalis & Belgian isolate 4 & - & ++++ \\
\hline G. vaginalis & Belgian isolate 5 & - & ++++ \\
\hline G. vaginalis & Belgian isolate 6 & - & ++++ \\
\hline G. vaginalis & Belgian isolate 7 & - & +++ \\
\hline G. vaginalis & Belgian isolate 8 & - & +++ \\
\hline G. vaginalis & Belgian isolate 9 & - & ++++ \\
\hline G. vaginalis & Belgian isolate 10 & - & ++ \\
\hline G. vaginalis & Belgian isolate 11 & - & ++++ \\
\hline G. vaginalis & Belgian isolate 12 & - & +++ \\
\hline G. vaginalis & Belgian isolate 13 & - & +++ \\
\hline G. vaginalis & Belgian isolate 14 & - & ++ \\
\hline G. vaginalis & Belgian isolate 15 & - & +++ \\
\hline G. vaginalis & Belgian isolate 16 & - & +++ \\
\hline G. vaginalis & Belgian isolate 17 & - & ++++ \\
\hline G. vaginalis & Belgian isolate 18 & - & ++++ \\
\hline Atopobium vaginae & CCUG $38953^{\top}$ & - & - \\
\hline A. vaginae & CCUG $42099^{\top}$ & - & - \\
\hline A. vaginae & CCUG $44116^{\top}$ & - & - \\
\hline A. vaginae & Clinical isolate & - & - \\
\hline Bacillus cereus & - & - & - \\
\hline Enterobacter aerogenes & CECT $684^{\top}$ & - & - \\
\hline Escherichia coli O157:H7 & NCTC $12900^{\top}$ & - & - \\
\hline Staphylococcus aureus & CECT $976^{\top}$ & - & - \\
\hline S. aureus & CECT $86^{\top}$ & - & - \\
\hline Shigella flexneri & ATCC $12022^{\top}$ & - & - \\
\hline Listeria monocytogenes & - & - & - \\
\hline L. monocytogenes & CECT $5873^{\top}$ & - & - \\
\hline L. seeligeri & CECT $917^{\top}$ & - & - \\
\hline Klebsiella pneumoniae subsp. ozaenae & ATCC $11296^{\top}$ & - & - \\
\hline Salmonella Typhi & - & - & - \\
\hline S. enterica & - & - & - \\
\hline Escherichia coli & CECT $434^{\top}$ & - & - \\
\hline Prevotella bivia & ATCC $29303^{\top}$ & - & - \\
\hline Mobiluncus mulieris & ATCC $26-9^{\top}$ & - & - \\
\hline Fusobacteria nucleatum & Clinical isolate & - & - \\
\hline
\end{tabular}

The PNA Probe (Lac663 and Gar162) efficiencies were tested in triplicate experiments for each strain, with the following hybridization PNA FISH qualitative evaluation: (-) Absence of hybridization; (++) Moderate hybridization; (+++) Good hybridization; (++++) Optimal hybridization. The table shows the median value from the three experiments for each strain.

spread on epoxy coated microscope glass slides (Thermo Scientific, USA). For mixed samples (see Table 3), $10 \mu \mathrm{L}$ of the final suspension from each strain suspension (prepared as previously referred) for the selected mixed sample were spread on glass slides. The slides were air-dried prior to fixation. Next, the smears were immersed in $4 \%$ (wt/vol) paraformaldehyde (Fisher Scientific, United Kingdom) followed by $50 \%$ (vol $/ \mathrm{vol}$ ) ethanol (Fisher Scientific, United
Kingdom) for $10 \mathrm{~min}$ at room temperature on each solution. After the fixation step, the samples were covered with $20 \mu \mathrm{L}$ of hybridization solution containing $10 \%$ (wt/vol) dextran sulphate (Fisher Scientific, United Kingdom), $10 \mathrm{mM} \mathrm{NaCl}$ (Sigma, Germany), 30\% (vol/vol) formamide (Fisher Scientific, United Kingdom), 0.1\% (wt/vol) sodium pyrophosphate (Fisher Scientific, United Kingdom), $0.2 \% \quad(\mathrm{wt} / \mathrm{vol}$ ) polyvinylpyrrolidone (Sigma, 
Table 2 Theoretical specificity and sensitivity of several primers and probes for Lactobacillus and Gardnerella spp. detection

\begin{tabular}{|c|c|c|c|c|c|c|c|}
\hline Probe & Type & Sequence $\left(5^{\prime} \rightarrow 3^{\prime}\right)$ & $\begin{array}{l}\text { No. of Lactobacillus } \\
\text { strains detected }^{\text {a }}\end{array}$ & $\begin{array}{l}\text { No. of non- Lactobacillus } \\
\text { strains detected }^{\text {a }}\end{array}$ & $\begin{array}{l}\text { Specificity } \\
(\%)^{\mathrm{a}}\end{array}$ & $\begin{array}{l}\text { Sensibility } \\
(\%)^{\mathrm{a}}\end{array}$ & $\begin{array}{l}\text { Reference } \\
\text { or source }\end{array}$ \\
\hline Lab158 ${ }^{\mathrm{b}}$ & DNA & GGTATTAGCA(C/T)CTGTTTCCA & 11,991 & 7,165 & $99.30^{9}$ & $92.69^{9}$ & {$[28]$} \\
\hline LGC354A & DNA & TGGAAGATTCCCTACTGC & 12,701 & 12,329 & $98.79^{9}$ & $98.18^{\mathrm{g}}$ & [29] \\
\hline$\angle A B 759^{\circ}$ & DNA & CTACCCATRCTITCGAGCC & 10,371 & 2,823 & $99.72^{9}$ & $80.17^{g}$ & {$[30]$} \\
\hline $\begin{array}{l}\text { Name not } \\
\text { available }\end{array}$ & PNA & CCATTGTGGAAGATTC & 12,930 & 14,880 & $98.54^{9}$ & $99.95^{9}$ & [31] \\
\hline Lac663 & PNA & ACATGGAGTTCCACT & 11,837 & 3,548 & $99.65^{9}$ & $91.50^{\mathrm{g}}$ & [26] \\
\hline GardV & DNA & CCACCGTTACACCGAGAA & 20 & 39 & 99.99 & 50.00 & [10] \\
\hline G.vag1008 ${ }^{f}$ & DNA & CTGCAGAGATGTGGTTTCCYTTCG & 39 & 7 & 100.00 & 97.50 & [32] \\
\hline G.vag198 & DNA & CCACTAAACACTITCCCAACAAGA & 34 & 0 & 100.00 & 85.00 & [6] \\
\hline GV003 & DNA & AGACGGCTCCATCCCAAAAGGGTT & 32 & 0 & 100.00 & 80.00 & [33] \\
\hline Gard162 & PNA & CAGCATTACCACCCG & 38 & 1 & 100.00 & 95.00 & This work \\
\hline
\end{tabular}

${ }^{a}$ Calculated through ProbeMatch/, last accession, May 2012) with the following data set options: Strain - Both; Source - Both; Size - > 1200 bp; Quality - Both.

$b$ DNA probe that also detects members of Enterococcus, Pediococcus, Weissella, Vagococcus, Leuconostoc and Oenococcus spp. used by Lebeer et al. [34].

' DNA probe mainly detecting members of Lactobacillales and Bacillales, such as Lactobacillus spp., used in Olsen et al. [35].

${ }^{e}$ DNA probe also detects members of Ruminococcaceae sp. and Pediococcus sp. used in Quevedo et al. [36]; The R symbol of the DNA probe sequence may be Adenosine or Guanosine, therefore Quevedo et al. [36] used a degenerate base in the sequence of the DNA probe to detect Lactobacillus spp.

${ }^{f}$ The $\mathrm{Y}$ symbol of the DNA probe sequence may be Cytidine or Thymidine, therefore Fredricks et al. [6] used a degenerate base in the sequence of the DNA probe to detect $G$. vaginalis

${ }^{g}$ Values determined in Machado et al.[26].

Germany), 0.2\% (wt/vol) ficoll (Sigma, Germany), $5 \mathrm{mM}$ disodium EDTA (Sigma, Germany), 0.1\% (vol/vol) triton $\mathrm{X}-100$ (Sigma), $50 \mathrm{mM}$ Tris- $\mathrm{HCl}$ (at $\mathrm{pH} 7.5$; Sigma, Germany) and $200 \mathrm{nM}$ of the PNA probe. Subsequently, the samples on glass slides were covered with coverslips and incubated in moist chambers at the hybridization temperature under analysis (from $50^{\circ} \mathrm{C}$ to $72^{\circ} \mathrm{C}$ ) during a range of hybridization times (from 230 to $180 \mathrm{~min}$ ). Next, the coverslips were removed and a washing step was performed by immersing the slides in a pre-warmed washing solution for $30 \mathrm{~min}$ at the same temperature of the hybridization step. This solution consisted of $5 \mathrm{mM}$ Trisbase (Fisher Scientific, United Kingdom), $15 \mathrm{mM} \mathrm{NaCl}$ (Sigma, Germany) and 0.1\% (vol/vol) triton X-100 (at pH 10; Sigma, Germany). Finally, the glass slides were allowed to air dry.

A FISH procedure in suspension was developed and optimized according to the previous work of Almeida and colleagues $[27,37]$ and to the results obtained for the FISH procedure on glass slides described above. Hybridization was performed at $60^{\circ} \mathrm{C}$ for $90 \mathrm{~min}$ and for washing $\left(60^{\circ} \mathrm{C}\right.$ for $30 \mathrm{~min}$ ) and a fresh solution was prepared less than 24 $\mathrm{h}$ before use. The suspension samples were stored at $4^{\circ} \mathrm{C}$ in the dark for a maximum of $24 \mathrm{~h}$ before microscopic observation/visualization. Both hybridization procedures (in glass slides and in suspension) are able to detect lactobacilli and G. vaginalis strains. While glass slide hybridization is the more commonly used technique in analytical laboratories [27], hybridization in suspension is frequently used to avoid autofluorescence background in complex matrix samples, besides being the hybridization technique used in flow cytometry $[27,37]$.

\section{Microscopic visualization}

Prior to microscopy, one drop of non-fluorescent immersion oil (Merck, Germany) was added to either slides or filters and covered with coverslips. Microscopic visualization was performed using an Olympus BX51 (Olympus Portugal SA, Porto, Portugal) epifluorescence microscope equipped with a CCD camera (DP72; Olympus) and filters capable of detecting the two PNA probes (BP 470-490, FT500, LP 516 sensitive to the Alexa Fluor 488 molecule attached to the Lac663 probe and BP 530-550, FT 570, LP 591 sensitive to the Alexa Fluor 594 molecule attached to the Gard162 probe).

Other filters (such as BP 365-370, FT 400, LP 421) present in the microscope, that are not capable of detecting the probe fluorescent signal were used to confirm the absence of autofluorescence. In each experimental assay, a negative control was performed simultaneously in which all the steps described above were carried out, but where no probe was added in the hybridization step. All images were acquired using Olympus CellB software using a total magnification of $\times 1000$.

\section{Experimental assessment of probe specificity and sensitivity}

After the hybridization optimization, the specificity and sensitivity of the PNA Lac663 and Gard162 probes were tested using 36 representative strains from the genus Lactobacillus, 22 representative strains from Gardnerella vaginalis (the only species of the genus Gardnerella [4]) and 27 representative strains from other related genera (see Table 1), of which 16 belonged to the order Lactobacillales and the other are common pathogens usually found in 
Table 3 Results of the Lac663 and Gard162 probes specificity test in artificial mixed samples

\begin{tabular}{|c|c|c|c|}
\hline \multirow[t]{2}{*}{ Species in the artificial mixed samples } & \multirow{2}{*}{$\begin{array}{l}\text { Bacteria strain } \\
\text { collection codes }\end{array}$} & \multicolumn{2}{|c|}{ Multiplex PNA-FISH assay } \\
\hline & & Lac663 Probe efficiency & Gard162 Probe efficiency \\
\hline L. pentosus; & CECT $4023^{\top}$; - & ++++ & ++++ \\
\hline \multicolumn{4}{|l|}{ G. vaginalis 51} \\
\hline L. casei; & CECT $5275^{\top} ;-$ & ++++ & ++++ \\
\hline \multicolumn{4}{|l|}{ G. vaginalis 101} \\
\hline L. rhamnosus; & CECT $288^{\top} ;-$ & ++++ & ++++ \\
\hline \multicolumn{4}{|l|}{ G. vaginalis $A M D$} \\
\hline L. crispatus; & ATCC $33820^{\top} ;-$ & ++++ & ++++ \\
\hline \multicolumn{4}{|l|}{ G. vaginalis ATCC } \\
\hline L. delbrueckii sub. delbrueckii; Atopobium vaginae & ATCC $9649^{\top}$; CCUG $38953^{\top}$ & +++ & - \\
\hline L. acidophilus; & ATCC $4356^{\top}$; CCUG $42099^{\top}$ & ++++ & - \\
\hline \multicolumn{4}{|l|}{ A. vaginae } \\
\hline L. gasseri; & ATCC $9857^{\top}$; CCUG $44116^{\top}$ & ++++ & - \\
\hline \multicolumn{4}{|l|}{ A. vaginae } \\
\hline L. paracasei sub. paracasei; & CCUG $27320^{\top} ;-$ & +++ & $-/+$ \\
\hline \multicolumn{4}{|l|}{ L. lactis 53} \\
\hline L. rhamnosus; & ATCC $7469^{\top}$; CECT $410^{\top}$ & ++++ & - \\
\hline \multicolumn{4}{|l|}{ E. faecium } \\
\hline L. reuteri; & NCFB $2656^{\top} ;$ & +++ & - \\
\hline E. coli O157:H7 & NCTC $12900^{\top}$ & & \\
\hline S. aureus; & CECT $976^{\top} ;-$ & - & ++++ \\
\hline \multicolumn{4}{|l|}{ G. vaginalis 51} \\
\hline Shigella; & ATCC $12022^{\top} ;-$ & - & ++++ \\
\hline \multicolumn{4}{|l|}{ G. vaginalis 101} \\
\hline L. seeligeri; & CECT $917^{\top} ;-$ & - & ++++ \\
\hline \multicolumn{4}{|l|}{ G. vaginalis $A M D$} \\
\hline E. aerogenes; & CECT $684^{\top} ;-$ & - & ++++ \\
\hline \multicolumn{4}{|l|}{ G. vaginalis ATCC } \\
\hline L. pentosus; & CECT 4023'; & ++++ & ++++ \\
\hline G. vaginalis ATCC; & $-i$ & & \\
\hline E. faecalis & CECT $184^{\top}$ & & \\
\hline L. casei; & CECT $5275^{\top}$ & ++++ & ++++ \\
\hline G. vaginalis $A M D$; & $-i$ & & \\
\hline A. vaginae & CCUG $38953^{\top}$ & & \\
\hline L. rhamnosus; & CECT 288 & ++++ & ++++ \\
\hline G. vaginalis 101; & $-;$ & & \\
\hline A. vaginae & CCUG 42099 & & \\
\hline L. crispatus; & ATCC $33820^{\top}$ & ++++ & ++++ \\
\hline G. vaginalis 51; & $-i$ & & \\
\hline A. vaginae & CCUG $44116^{\top}$ & & \\
\hline L. casei; & CECT $5275^{\top}$ & ++++ & - \\
\hline L. mesenteroides; & $-i$ & & \\
\hline A. vaginae & CCUG $38953^{\top}$ & & \\
\hline
\end{tabular}

The PNA probe (Lac663 and Gar162) efficiencies were tested in triplicate experiments for each strain, with the following hybridization PNA FISH qualitative evaluation: (-) Absence of hybridization; (+) Poor hybridization; (+++) Good hybridization; (++++) Optimal hybridization. Median values from the three experiments for each strain are shown in the table. 
clinical samples, specifically strains from the following genera: Atopobium, Bacillus, Lactococcus, Enterobacter, Enterococcus, Escherichia, Fusobacterium, Klebsiella, Leuconostoc, Listeria, Mobiluncus, Prevotella, Salmonella, Shigella, Staphylococcus and Streptococcus [38-40]. All experiments were performed in triplicate at identical conditions and the experimental specificity and sensitivity were calculated.

\section{Detection of Lactobacillus spp. and G. vaginalis adhered to HeLa cell line}

The application of cellular lines is a standard procedure that has already been used to mimic vaginal epithelium at several in vitro studies [41-43]. So, HeLa epithelial cells (from American Tissue Culture Collection, ATCC) were cultured at $37^{\circ} \mathrm{C}$, in $5 \% \mathrm{CO}_{2}$ ( $\mathrm{vol} / \mathrm{vol}$ ), in Dulbecco's modified Eagle's medium (DMEM; Quality Biological, USA) supplemented with 10\% FBS (vol/vol) and 1 IU penicillin/ streptomycin $\mathrm{ml}^{-1}$ (MediaTech, Germany). Aliquots of $1 \mathrm{ml}$ from HeLa epithelial cells were seeded into 24-well tissue culture plates (Frilabo, Portugal) containing glass slides $(12 \mathrm{~mm})$ at a density of $2 \times 10^{5}$ cells per well, and incubated at $37^{\circ} \mathrm{C}$ and $5 \% \mathrm{CO}_{2}$ (vol/vol) until the formation of a cell monolayer. The cultures were fed with fresh media every 48 hours. Simultaneously, several Lactobacillus (L. crispatus and L. iners) strains and G. vaginalis strain 5-1 were grown in MRS broth and BHI broth as described above. Prior to the adhesion assay, these broth cultures were harvested by centrifugation $(4,000 \mathrm{~g}, 12 \mathrm{~min}$, at room temperature) and washed twice with sterile phosphate buffer saline (PBS). Several standard concentrations of the bacteria were prepared in eukaryotic cell media (DMEM) and the optical density at $600 \mathrm{~nm}$ was adjusted using a microplate reader (Tecan, Portugal). When a HeLa cell monolayer was obtained, the cells were washed twice with $500 \mu \mathrm{l}$ of sterile PBS to remove non adhered cells and culture media. Next, aliquots of $250 \mu$ l of cell culture media with a known concentration of a Lactobacillus strain and G. vaginalis $5-1$ strain $\left(1 \times 10^{3}\right.$ to $1 \times 10^{9} \mathrm{CFU} /$ $\mathrm{ml}$; see Table 4) were added to each well with the washed cell monolayer from the 24-well tissue culture plate. Then the 24-well tissue culture plate was incubated for $30 \mathrm{~min}$ at $37^{\circ} \mathrm{C}$ in anaerobic conditions and $120 \mathrm{rpm}$. Finally, each well of the incubated plate was carefully washed twice with $500 \mu \mathrm{l}$ of sterile PBS to remove non-adherent bacteria. The glass slides containing the adhered bacteria and eukaryotic cells were fixed and hybridized with both PNA probes and observed in fluorescence microscopy, as referred above. An additional 4',6-diamidino-2-phenylindole (DAPI; Sigma, Portugal) staining step was done at the end of the hybridization procedure, covering each of the glass slides with $10 \mu \mathrm{l}$ of DAPI for $5 \mathrm{~min}$ at room temperature in the dark, followed by immediate observation in the fluorescence microscope. All these assays were repeated three times, on separate days, with three fields of view assessed each time.

\section{Results}

\section{In silico analysis of PNA probes}

The Lac663 probe showed a theoretical sensitivity and specificity of $91.5 \%$ and $99.7 \%$, respectively, which corroborates the previously reported values [26]. Actually, this publication shows that these probes match the best values of the existing Lactobacillus probes. Gard162 probe presented a theoretical sensitivity of $95.0 \%$ and specificity of $100 \%$. The theoretical specificity and sensitivity of these two probes and those developed in other studies were calculated as previously described by Almeida et al. [27] and are listed in Table 2. ProbeMatch tool, from RPDII (http://rdp.cme.msu.edu/probematch/; last accession, May 2012), was used with the following data set options: Strain - Both; Source - Both; Size - > 1200 bp; Quality - Both. For Lactobacillus probes, the specificity and sensitivity values previously determined [26], were considered.

\section{FISH Protocol optimization and autofluorescence-related factors}

FISH protocols on slides and in suspension were adapted from previous protocols developed by Almeida et al. [37], due to the crucial importance of fixation and hybridization

Table 4 Efficiency of the Lactobacillus spp. and G. vaginalis detection in adhesion assays with HeLa cell line

\begin{tabular}{ccc}
\hline \multicolumn{2}{c}{ Concentration of cells (CFU/mI) } & Multiplex PNA-FISH assay \\
\hline L. crispatus & G. vaginalis $\mathbf{5 - 1}$ & Lac663 Probe efficiency \\
\hline $1 \times 10^{9}$ & $1 \times 10^{9}$ & +++ \\
\hline $1 \times 10^{5}$ & $1 \times 10^{5}$ & +++ \\
\hline $1 \times 10^{3}$ & $1 \times 10^{3}$ & ++++ \\
\hline L. iners & G. vaginalis 5-1 & Lac663 Probe efficiency \\
\hline $1 \times 10^{9}$ & $1 \times 10^{9}$ & +++ \\
\hline $1 \times 10^{5}$ & $1 \times 10^{5}$ & +++ \\
\hline $1 \times 10^{3}$ & $1 \times 10^{3}$ & +++ \\
\hline
\end{tabular}

The PNA probe (Lac663 and Gar162) efficiencies were tested in each sample with the following hybridization PNA FISH qualitative evaluation: (++) Moderate hybridization; $(+++)$ Good hybridization; (++++) Optimal hybridization. The table shows the median value from the three experiments for each sample. 
conditions for an efficient multiplex FISH with different probes. From an initial temperature range of 50 to $72^{\circ} \mathrm{C}$ and an incubation time range between 30 and $180 \mathrm{~min}$, the best hybridization conditions were set as a moist chamber temperature of $60^{\circ} \mathrm{C}$ during $90 \mathrm{~min}$ of incubation (data not shown). Hybridization conditions started to reveal strong signal-to-noise ratio at $59^{\circ} \mathrm{C}$ to $61^{\circ} \mathrm{C}$ from 30 min of incubation up to $120 \mathrm{~min}$, reaching its peak at $60^{\circ} \mathrm{C}$ during $90 \mathrm{~min}$ of incubation. Hybridization conditions above $60^{\circ} \mathrm{C}$ and $90 \mathrm{~min}$ were also efficient, but the signal-to-noise ratio appeared to decrease beyond the selected values of time and temperature. Both hybridization protocols (on slides and in suspension) revealed the same results and pitfalls, as discussed below (some examples are shown in Figure 1).

\section{Experimental determination of probe specificity and sensitivity}

As shown in Table 1, the Lac663 probe was able to detect all Lactobacillus strains and cross hybridization was found only for Streptococcus thermophilus B, as it was previously reported [26]. Based on these results, an experimental sensitivity of $100 \%$ ( $95 \%$ CI, 88.0 to $100.0 \%$ ) and specificity of 98.0\% (95\% CI, 87.8 to $99.9 \%$ ) were obtained for the Lac663 PNA probe. The Gard162 probe hybridized with all G. vaginalis strains, whereas no hybridization was observed for the other species tested. Therefore, this probe revealed a sensitivity of $100 \%$ ( $95 \% \mathrm{CI}, 81.5$ to $100.0 \%)$ and a specificity of $100 \%$ ( $95 \%$ CI, 92.8 to $100 \%$ ).

\section{Detection of Lactobacillus spp. and G. vaginalis by Multiplex FISH}

Once the hybridization procedure was fully optimized, the multiplex methodology was also tested against mixed bacterial cultures (containing Lactobacillus or/ and G. vaginalis cells together with others species, see Table 3) and infected tissue cell line (Table 4). Lac663 and Gard162 probes selectively bound to Lactobacillus and G. vaginalis strains, respectively. The fluorescence signal was easily observable (Figure 2) and no cross hybridization
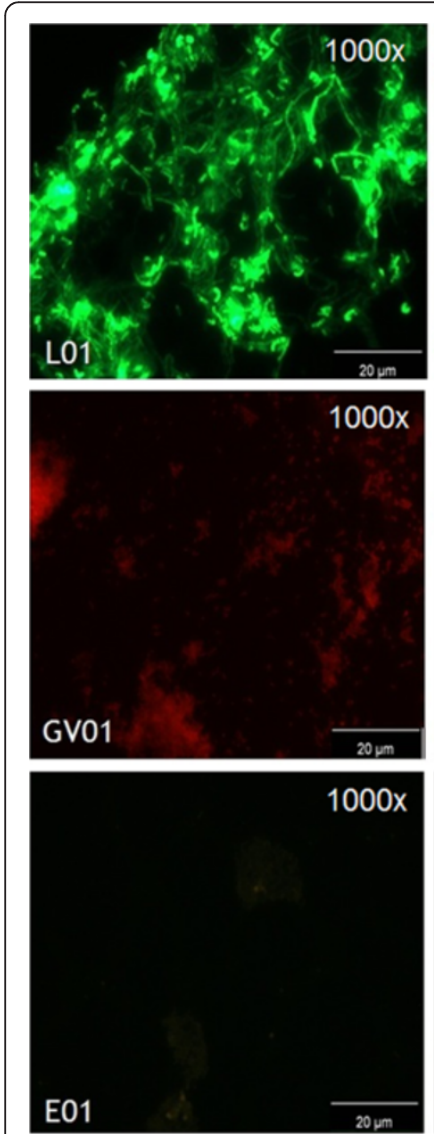
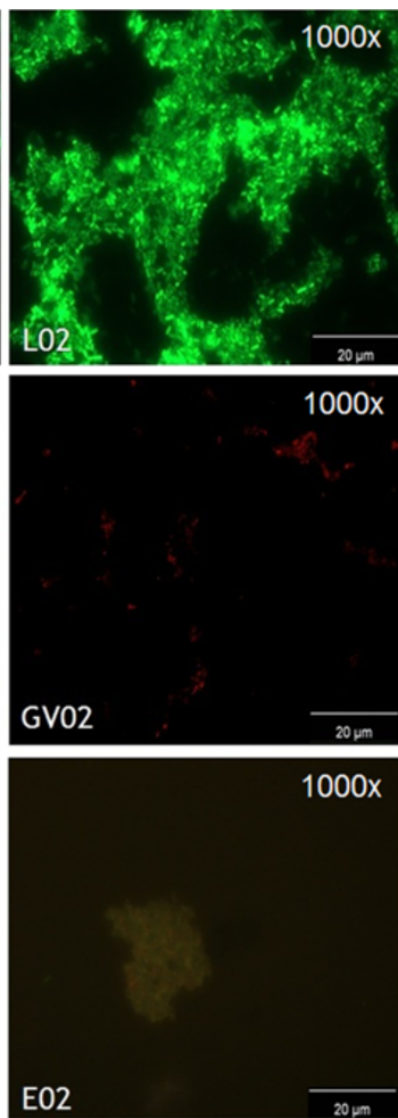
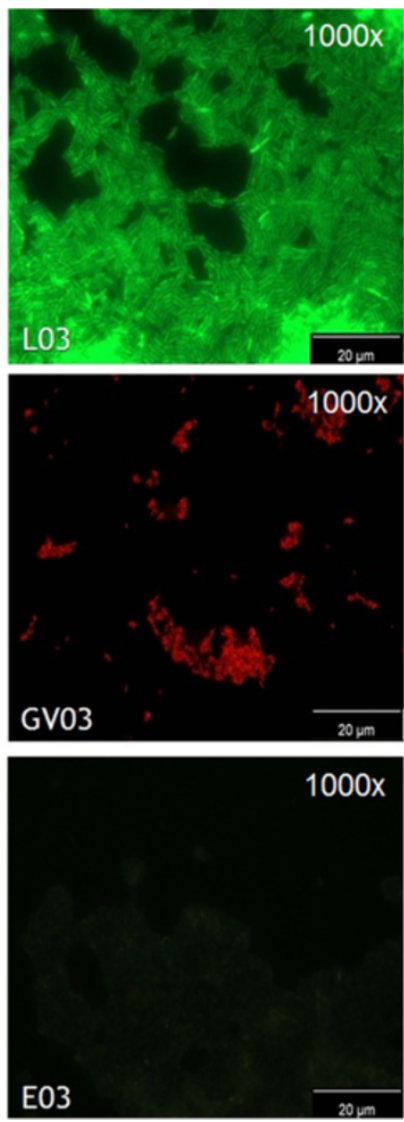
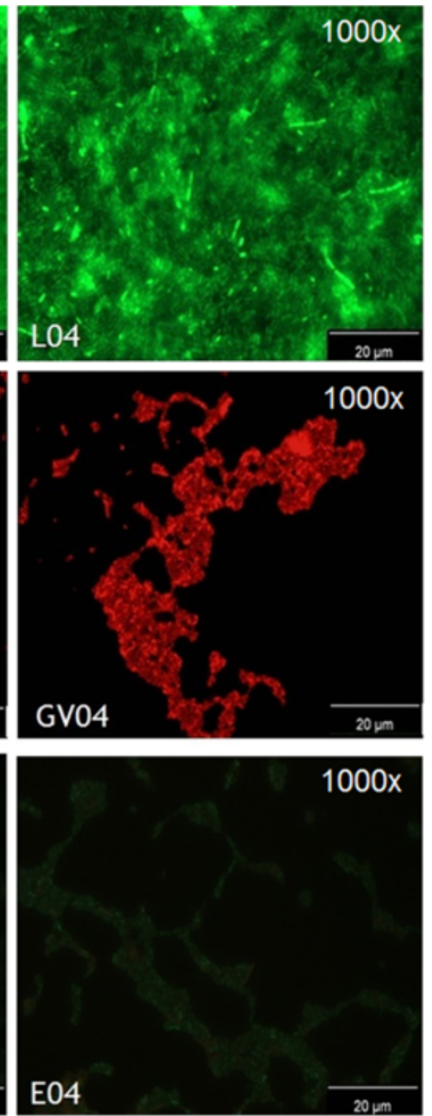

Figure 1 Fluorescence microscopy pictures of Lactobacillus species, G. vaginalis and other related bacteria by PNA probes.

L01, L. paracasei CECT227; L02, L. delbrueckii ATCC9649; L03, L. murinus ATCC35020; L04, L. salivarius 438; GV01, G. vaginalis 5-1; GV02, G. vaginalis ATCC; GV03, Belgian G. vaginalis isolate 17; GV03, Belgian G. vaginalis isolate 18; E01, Streptococcus thermophilus A; E02, Leuconostoc mesenteroides; E03, Enterococcus faecium; E04, Enterococcus faecalis. The Lac663 and Gard162 PNA probes were associated with Alexa Fluor 488 and 594 fluorochromes, respectively. 

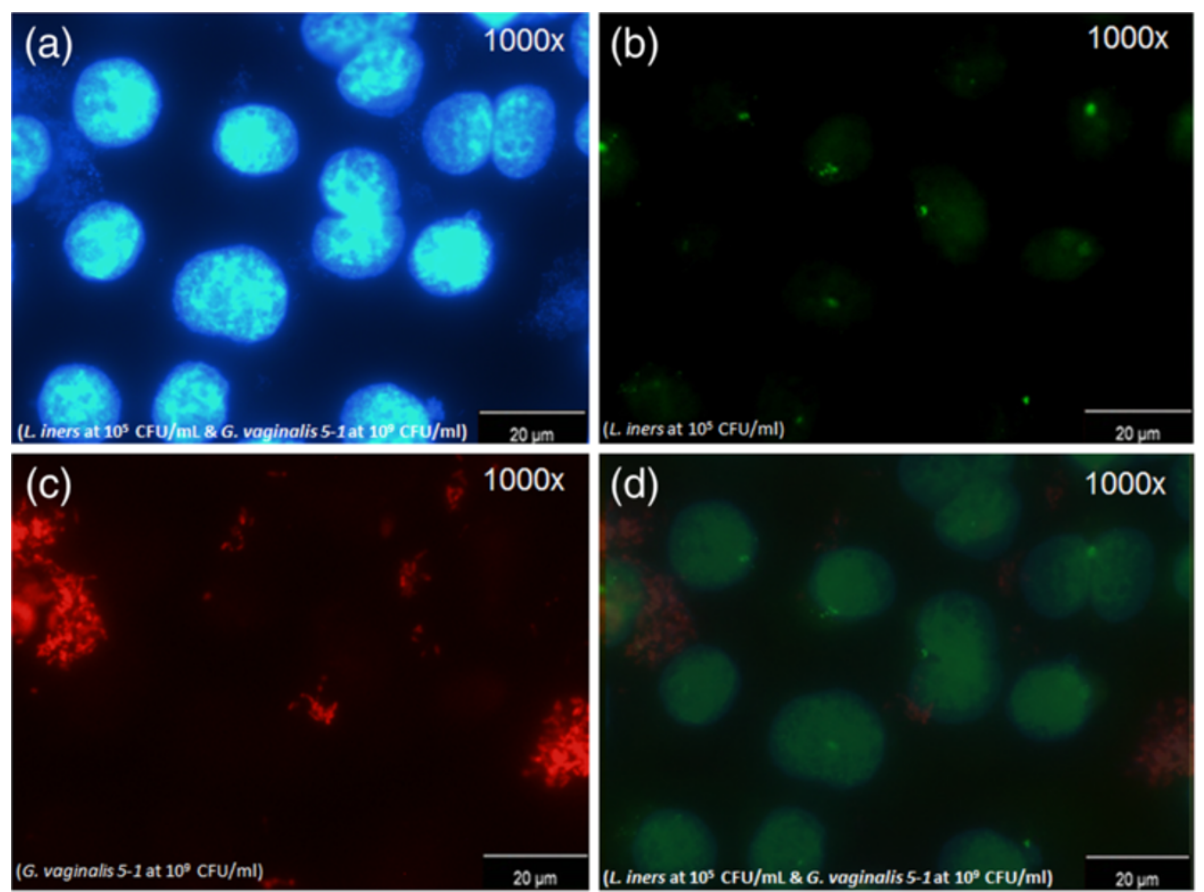

Figure 2 Fluorescence microscopy pictures with Lactobacillus spp. and G. vaginalis at different concentrations against HeLa cell line. (a), blue filter; (b) green filter; (c) red filter; (d) overlay of the three previous filters. These fluorescence microscopy pictures were taken in the same microscopic field with $L$. iners and G. vaginalis 5-1 from culture strain collection at different concentrations against HeLa cell line by DAPI staining and specific PNA probes (Lac663 and Gard162), associated with Alexa Fluor 488 and 594 fluorochromes, respectively.

with other species was detected (see Table 3). Additionally, the multiplex also performed well in the presence of HeLa cells (Table 4) for all the bacterial concentrations evaluated $\left(1 \times 10^{3}\right.$ until $\left.1 \times 10^{9} \mathrm{CFU} / \mathrm{ml}\right)$, confirming the in silico analysis of the PNA probes previously elaborated.

\section{Discussion}

In silico and in vitro probe specificity and sensibility

Fluorescence microscopy has become a widely used technique for direct detection of bacteria in complex samples. In fact, many authors demonstrated the efficiency of FISH methodology for the analysis of lactobacilli and G. vaginalis $[6,10,32,34,44-47]$. However, the herein described multiplex approach may be the simpler to perform and still has high specificity for lactobacilli and G. vaginalis detection.

As shown in Table 1, the Lac663 and Gard162 probes bound highly specific to each target strain. Only Lac663 showed cross-hybridization with $S$. thermophilus B. However, $S$. thermophilus coccus morphology allows a clear differentiation from Lactobacillus spp., which has a rodshaped morphology (with the exception of $L$. iners). Importantly, the Lac663 probe did not hybridize with several bacterial species from the Bacilli class and also with other common vaginal pathogenic bacteria, providing further evidence of its usefulness for Lactobacillus spp. detection in clinical samples.
Furthermore, the Gard162 probe showed hybridization with all $G$. vaginalis strains and no cross-hybridization was observed to other species, including other related pathogenic bacteria which may be present in the vaginal microflora, such as $A$. vaginae, $P$. bivia, M. mulieris and F. nucleatum (see Table 1). It is worth to mention that in silico analysis of the Gard162 probe only identified one non-target strain as match, more precisely Bifidobacterium indicum HM534842 (RDPII ID: S002908348). However, B. indicum is not a common bacterium from vaginal microflora, as it is usually present in the gut [48]. Recently a strong association between the bacterial loads in the vagina and rectum of pregnant women was described [49]. Although some gut bacteria such as Escherichia coli [48] have been associated with vaginal infections, $B$. indicum has not been described as a pathogenic bacterium [50]. The FISH efficiency and hybridization quality for the Gard162 probe, either alone or together with the Lac663 probe, confirmed the applicability of these two probes together in a multiplex PNA-FISH (see Figures 1 and 2).

As shown in Table 2, sensitivity and specificity equations allowed the comparison between our PNA probes and other published ones for $G$. vaginalis detection. For the Lactobacillus probe, this comparison had already been performed [26] and the Lac663 theoretical performance was found to be similar to other probes reported for Lactobacillus genus detection, but with a highest 
specificity. Also, Lab158, LGC354 and PNA Burton et al. [31] probes were found to cross-hybridize with one strain (RDPII ID: S000536416) from G. vaginalis, which might be incompatible with a multiplex approach to be used in vaginal samples. On the other hand, it is possible that this $G$. vaginalis strain was a misidentified $L$. iners strain, because confusion between both species has been reported [51].

Gard162 theoretical performance in specificity (100\%) was found to be similar to other probes for G. vaginalis detection that have been previously reported (Table 2). G.vag1008 is the only probe with higher sensitivity (97.5\%) than our probe, being able to detect one more G. vaginalis strain. This higher sensitivity is due to the presence of a degenerate oligonucleotide in the sequence of the probe (see Table 2), allowing G.vag1008 to act as two different sequence probes. However, G.vag1008 has 24 oligonucleotides (i.e. 9 nucleotides more than our probe) and it is a DNA probe, which penetrates the cell wall less efficiently [52] and implies need for the use of long hybridization periods.

GardV probe detected species from several bacterial genera present in vaginal samples, such as Alloscardovia, Parascardovia and Scardovia spp. [53]. G.vag1008 probe hybridized with Aeriscardovia spp. that may also be found in vaginal samples [53] and therefore this represents an important pitfall for the G. vaginalis detection with such probes.

It is important to notice that our Gard162 probe is the first PNA probe specifically designed for $G$. vaginalis detection. Other PNA probes for the detection of lactobacilli $[31,46]$ revealed several disadvantages when compared to Lac663 probe, as we shown before [26].

\section{Multiplex FISH detection}

Although numerous authors attempted to correlate differences between healthy and BV vaginal samples [54-57], no consensus was achieved, except that biofilm formation of G. vaginalis and a decrease in lactobacilli number could be considered as the initial stages in the pathogenesis of BV [10,58]. Swidsinski and colleagues already conducted an international follow-up study in which vaginal samples from several BV patients were analyzed by DNA-based FISH and a dense as well as active bacterial biofilm on vaginal mucosa was detected, primarily consisting of G. vaginalis [47]. Therefore, multiplex FISH to analyze G. vaginalis biofilm establishment and subsequently lactobacilli replacement appeared to be a useful molecular methodology for BV diagnosis in vaginal samples. Although several authors already developed specific probes for G. vaginalis and Lactobacillus spp. detection for FISH, our multiplex method presented new improvements on the method (see Table 2).
Due to the difficulty to obtain fresh vaginal samples diagnosed with BV, we devised an in vitro experiment mimicking the shift from healthy vaginal flora to BV HeLa cells were incubated with different concentrations of G. vaginalis and Lactobacillus strains (L. crispatus and $L$. iners), ranging from normal to BV vaginal microflora contents $\left(1 \times 10^{3}\right.$ to $1 \times 10^{9} \mathrm{CFU} / \mathrm{ml}$; see Table 4$)$. The HeLa cell line is an established tool in experimental research with lactobacilli. It has not only been used to study attachment of several Lactobacillus species, but also of other pathogens [41-43]. The Lactobacillus strains used here were selected because high concentrations of L. crispatus (in conjugation with low loads or absence of $G$. vaginalis) are usually associated to the normal vaginal microflora while high concentrations of L. iners (in conjugation with high loads of G. vaginalis) are commonly associated to the microflora of BV diagnosed women $[4,7,51]$. The efficiency of our multiplex PNA-FISH methodology was demonstrated by ability of the PNA probes to hybridize in a large range of Lactobacillus spp. and G. vaginalis concentrations, even in the presence of epithelial cells (see Table 4). Swidsinski and colleagues $[10,47]$ used a multiplex FISH methodology to study BV biofilms. A drawback of their approach is that it requires pre-treatment with lysozyme before fixation and the use of urine or paraffin-embedded samples, in opposition of our methodology that do not require a pre-treatment for FISH analysis. These experimental steps increase analysis time and decrease FISH efficiency for Lactobacillus spp. and G. vaginalis strains detection, due to the lower number of cells available for hybridization. Another DNA hybridization test for vaginal infection was studied by Witt and colleagues that evaluated the Affirm VPIII Kit [59], which detected G. vaginalis, Candida spp. and Trichomonas vaginalis in clinical samples, using two distinct single-stranded nucleic acid probes for each organism, which makes the analysis more complex and vulnerable to experimental pitfalls. This validated method showed sensitivity and specificity values for G. vaginalis of $89.5 \%$ and $97.1 \%$, respectively, both lower than our Gard162 experimental values (95.0\% and 100\%, respectively). Furthermore, Fredricks and colleagues developed a FISH methodology for molecular identification of unknown bacteria associated with BV [6], using DNA probes Eub338-Cy5 and G.vag198Cy3. However, the Eub338 is an unspecific probe used to detect Lactobacillus spp., detecting all species of the order Bacillales, and G.vag198 corresponds to a twenty five oligonucleotide probe with high specificity (100\%) but with low sensitivity (85.0\%) when compared to our probe (see Table 2). Both these probes worked together at a hybridization temperature of $45^{\circ} \mathrm{C}$, which may easily lead to the occurrence of false positive results. Moreover, previous studies have shown that probes with $\mathrm{Cy}$ 
fluorochromes present a lower fluorescence signal than those with the corresponding Alexa Fluor [60].

To conclude, our main purpose was achieved by demonstrating the in vitro applicability of the PNA multiplex methodology for detection of Lactobacillus species and G. vaginalis in the presence of the HeLa epithelial cell line and other taxonomically related or pathogenic bacterial strains commonly found in vaginal samples. These in vitro results confirmed the previous in silico analysis from Lac663 and Gard162 probes.

\section{Conclusions}

In summary, the use of the PNA multiplex FISH assay described here significantly increases the specificity and sensitivity of the detection of Lactobacillus spp. and G. vaginalis strains in mixed samples and no interference was observed in the presence of human epithelial cells. As previously referred, there are no consensual agreements regarding BV markers, except for lactobacilli number decrease and initial adherence, and consequent biofilm formation from G. vaginalis. Moreover, our approach allows a fast identification (approximately 3 hours) of the main bacteria involved in BV establishment. Further studies are necessary to detect BV biofilm formation in clinical samples and to characterize possible interactions with other unknown bacteria in the biofilm. The combination of our PNA-FISH methodology with EUB probe or other methodologies, such as electron microscopy, may help to better understand BV etiology.

\section{Competing interests}

This work has been submitted as a patent.

\section{Authors' contributions}

AM, CA, DS and AH conceived of the study and participated in its design and drafted the manuscript. AM and CA carried out the PNA probes design and PNA-FISH assays. DS and AH worked in the PNA-FISH assays and HeLa cellular line culture, respectively. MV, FH, MJV and LR provided the bacteria culture collection for the study and helped to draft the manuscript. NFA and NC conceived of the study and participated in its design and coordination and helped to draft the manuscript. All authors read and approved the final manuscript.

\section{Acknowledgements}

This work was supported by European Union funds (FEDER/COMPETE) and by national funds (FCT) under the project with reference FCOMP-01-0124FEDER-008991 (PTDC/BIA-MIC/098228/2008). AM acknowledges the FCT individual fellowship - SFRH/BD/62375/2009).

\footnotetext{
Author details

${ }_{1}^{1}$ IBB - Institute for Biotechnology and Bioengineering, Centre of Biological Engineering, University of Minho, Campus de Gualtar, Braga 4710-057, Portugal. ${ }^{2}$ LEPAE, Department of Chemical Engineering, Faculty of Engineering, University of Porto, rua Dr. Roberto Frias, Porto 4200-465, Portugal. ${ }^{3}$ Laboratory of Bacteriology Research, Faculty Medicine \& Health Sciences, University of Ghent, Ghent B-9000, Belgium. ${ }^{4}$ Laboratory of Veterinary Bacteriology and Mycology, Faculty of Veterinary Medicine, Ghent University, Merelbeke B9820, Belgium.
}

Received: 26 November 2012 Accepted: 27 March 2013 Published: 12 April 2013

\section{References}

1. Spiegel CA: Bacterial vaginosis. Clin Microbiol Rev 1991, 4:485-502.

2. Turovskiy $Y$, Noll KS, Chikindas ML: The etiology of bacterial vaginosis. J Appl Microbiol 2011, 110:1105-1128.

3. Vitali B, Pugliese C, Biagi E, Candela M, Turroni S, Bellen G, Donders GG, Brigidi $P$ : Dynamics of vaginal bacterial communities in women developing bacterial vaginosis, candidiasis, or no infection, analyzed by PCR-denaturing gradient gel electrophoresis and real-time PCR. Appl Environ Microbiol 2007, 73:5731-5741.

4. Oakley BB, Fiedler TL, Marrazzo JM, Fredricks DN: Diversity of human vaginal bacterial communities and associations with clinically defined bacterial vaginosis. Appl Environ Microbiol 2008, 74:4898-4909.

5. Ling Z, Kong J, Liu F, Zhu H, Chen X, Wang Y, Li L, Nelson KE, Xia Y, Xiang C: Molecular analysis of the diversity of vaginal microbiota associated with bacterial vaginosis. BMC Genomics 2010, 11:488-503.

6. Fredricks DN, Fiedler TL, Marrazzo JM: Molecular identification of bacteria associated with bacterial vaginosis. N Engl J Med 2005, 353:1899-1911.

7. De Backer E, Verhelst R, Verstraelen H, Alqumber MA, Burton JP, Tagg JR, Temmerman M, Vannechoutte M: Quantitative determination by real-time PCR of four vaginal Lactobacillus species, Gardnerella vaginalis and Atopobium vaginae indicates an inverse relationship between L. gasseri and L. iners. BMC Microbio/ 2007, 7:115. doi:10.1186/1471-2180-7-115.

8. Schwebke JR: New concepts in the etiology of bacterial vaginosis. Curr Infect Dis Rep 2009, 11:143-147.

9. Nugent R, Krohn M, Hillier S: Reliability of diagnosing bacterial vaginosis is improved by a standardized method of Gram stain interpretation. J Clin Microbiol 1991, 29:297-301.

10. Swidsinski A, Mendling W, Loening-Baucke V, Ladhoff A, Swidsinski S, Hale LP, Lochs H: Adherent biofilms in bacterial vaginosis. Obstet Gynecol 2005, 106:1013-1023.

11. Rosenstein IJ, Fontaine EA, Morgan DJ, Sheehan M, Lamont RF, TaylorRobinson D: Relationship between hydrogen peroxide-producing strains of lactobacilli and vaginosis-associated bacterial species in pregnant women. Eur J Clin Microbiol Infect Dis 1997, 16:517-522.

12. Patterson $J \mathrm{~L}$, Girerd PH, Karjane NW, Jefferson KK: Effect of biofilm phenotype on resistance of Gardnerella vaginalis to hydrogen peroxide and lactic acid. Am J Obstet Gynecol 2007, 197:170. e1-7.

13. Patterson JL, Stull-Lane A, Girerd PH, Jefferson KK: Analysis of adherence, biofilm formation and cytotoxicity suggests a greater virulence potential of Gardnerella vaginalis relative to other bacterial-vaginosis-associated anaerobes. Microbiol 2010, 156:392-399.

14. Nath J, Johnson KL: A review of fluorescence in situ hybridization (FISH): current status and future prospects. Biotech Histochem 2000, 75:54-78.

15. Justé A, Thommad B, Lievens B: Recent advances in molecular techniques to study microbial communities in food-associated matrices and processes. Food Microbiol 2008, 25:745-761.

16. Demidov W: PNA and LNA throw light on DNA. Trends Biotechnol 2003, 21:4-7.

17. Isacsson J, Cao H, Nordgren S, Svanvik N, Westman G, Kubista M, Sjöback R, Sehlstedt U: Rapid and specific detection of PCR products using light-up probes. Mol Cell Probes 2000, 14:321-328.

18. Rigby S, Procop GW, Haase G, Wilson D, Hall G, Kurtzman C, Oliveira K, Von Oy S, Hyldig-Nielsen JJ, Coull J, Stender H: Fluorescence in situ hybridization with peptide nucleic acid probes for rapid identification of Candida albicans directly from blood culture bottles. J Clin Microbio/ 2002, 40:2182-2186.

19. Stender H, Fiandaca M, Hyldig-Nielsen JJ, Coull J: PNA for rapid microbiology. J Microbiol Methods 2002, 48:1-17.

20. Oliveira K, Procop GW, Wilson D, Coull J, Stender H: Rapid identification of Staphylococcus aureus directly from blood cultures by fluorescence in situ hybridization with peptide nucleic acid probes. J Clin Microbiol 2002, 40:247-251

21. Wilson DA, Joyce MJ, Hall LS, Reller LB, Roberts GD, Hall GS, Alexander BD, Procop GW: Multicenter evaluation of a Candida albicans peptide nucleic acid fluorescent in situ hybridization probe for characterization of yeast isolates from blood cultures. J Clin Microbiol 2005, 43:2909-2912.

22. Lefmann M, Schweickert B, Buchholz P, Göbel B, Ulrichs T, Seiler P Theegarten D, Moter A: Evaluation of peptide nucleic acid-fluorescence in situ hybridization for identification of clinically relevant mycobacteria in clinical specimens and tissue sections. J Clin Microbiol 2006, 44:3760-3767. 
23. Peleg AY, Tilahun Y, Fiandaca MJ, D'Agata EMC, Venkataraman L, Moellering RC, Eliopoulos GM: Utility of peptide nucleic acid fluorescence in situ hybridization for rapid detection of Acinetobacter spp. and Pseudomonas aeruginosa. J Clin Microbiol 2009, 47:830-832.

24. Ashelford K, Weightman A, Fry J: PRIMROSE: a computer program for generating and estimating the phylogenetic range of 16S rRNA oligonucleotide probes and primers in conjunction with the RDP-II database. Nucleic Acids Res 2002, 30:3481-3489.

25. Cole J, Wang Q, Cardenas E, Fish J, Chai B, Farris RJ, Kulam-Syed-Mohideen AS, McGarrell DM, Marsh T, Garrity GM, Tiedje JM: The Ribosomal Database Project: improved alignments and new tools for rRNA analysis. Nucleic Acids Res 2009, 37:D141-D145.

26. Machado A, Almeida C, Carvalho A, Boyen F, Haesebrouck F, Rodrigues L, Cerca N, Azevedo NF: Fluorescence In Situ Hybridization Method Using a Peptide Nucleic Acid Probe for Identification of Lactobacillus spp. in Milk Samples. Int J of Food Microbiol 2013, 162:64-70.

27. Almeida C, Azevedo NF, Fernandes R, Keevil C, Vieira MJ: A fluorescence in situ hybridization method using a peptide nucleic acid probe for the identification of Salmonella spp. in a broad spectrum of samples. Appl Environ Microbiol 2010, 76:4476-4485.

28. Harmsen H, Elfferich P, Schut F, Welling G: A 16S rRNA-targeted probe for detection of lactobacilli and enterococci in faecal samples by fluorescent in situ hybridization. Microb Ecol Health D 1999, 11:3-12.

29. Meier H, Amann R, Ludwig W, Schleifer K: Specific oligonucleotide probes for in situ detection of a major group of gram-positive bacteria with low DNA G + C content. Syst Appl Microbiol 1999, 22:186-196.

30. Zijnge $V$, van Leeuwen MB, Degener JE, Abbas F, Thurnheer T, Gmur R, Harmsen HJ: Oral biofilm architecture on natural teeth. PLOS ONE 2010 5:e9321. doi:10.1371/journal.pone.0009321

31. Burton J, McCormick J, Cadieux P, Reid G: Digoxigenin-labelled peptide nucleic acid to detect lactobacilli PCR amplicons immobilized on membranes from denaturing gradient gel electrophoresis. Lett Appl Microbiol 2003, 36:145-149.

32. Fredricks DN, Fiedler TL, Thomas KK, Mitchell CM, Marrazzo JM: Changes in vaginal bacterial concentrations with intravaginal metronidazole therapy for bacterial vaginosis as assessed by quantitative PCR. J Clin Microbiol 2009, 47:721-726.

33. Sheiness D, Dix K, Watanabe S, Hillier SL: High levels of Gardnerella vaginalis detected with an oligonucleotide probe combined with elevated $\mathrm{pH}$ as a diagnostic indicator of bacterial vaginosis. J Clin Microbio/ 1992, 30:642-648.

34. Lebeer S, Verhoeven T, Claes I, De Hertogh G, Vermeire S, Buyse J, Van Immerseel F, Vanderleyden J, De Keersmaecker SC: FISH analysis of Lactobacillus biofilms in the gastrointestinal tract of different hosts. Lett Appl Microbiol 2011, 52:220-226.

35. Olsen $\mathrm{K}$, Henriksen M, Bisgaard M, Nielsen O, Christensen H: Investigation of chicken intestinal bacterial communities by $16 \mathrm{~S}$ rRNA targeted fluorescence in situ hybridization. Antonie van Leeuwenhoek 2008, 94:423-437.

36. Quevedo B, Giertsen E, Zijnge V, Lüthi-Schaller H, Guggenheim B, Thurnheer T, Gmur R: Phylogenetic group- and species-specific oligonucleotide probes for single-cell detection of lactic acid bacteria in oral biofilms. BMC Microbiol 2011, 11:14. doi:10.1186/1471-2180-11-14.

37. Almeida C, Azevedo NF, Iversen C, Fanning S, Keevil C, Vieira MJ: Development and application of a novel peptide nucleic acid Probe for the specific detection of Chronobacter genomospecies (Enterobacter sakazakii) in powdered infant formula. Appl Environ Microbiol 2009, 75:2925-2930

38. Byun R, Nadkarni MA, Chhour KL, Martin FE, Jacques NA, Hunter N: Quantitative analysis of diverse Lactobacillus species present in advanced dental caries. J Clin Microbiol 2004, 42:3128-3136.

39. McKechnie ML, Hillman R, Couldwell D, Kong F, Freedman E, Wang H, Gilbert GL: Simultaneous identification of 14 genital microorganisms in urine by use of a multiplex PCR-based reverse line blot assay. J Clin Microbiol 2009, 47:1871-1877.

40. Zozaya-Hinchliffe M, Lillis R, Martin DH, Ferris MJ: Quantitative PCR assessments of bacterial species in women with and without bacterial vaginosis. J Clin Microbiol 2010, 48:1812-1819.

41. Atassi F, Brassart D, Grob P, Graf F, Servin AL: Lactobacillus strains isolated from the vaginal microbiota of healthy women inhibit Prevotella bivia and Gardnerella vaginalis in coculture and cell culture. FEMS Immunol Med Microbiol 2006, 48:424-432.
42. Martín R, Sánchez B, Suárez JE, Urdaci MC: Characterization of the adherence properties of human Lactobacilli strains to be used as vaginal probiotics. FEMS Microbiol Lett 2012, 328:166-173.

43. Frick JS, Schenk K, Quitadamo M, Kahl F, Köberle M, Bohn E, Aepfelbacher M, Autenrieth IB: Lactobacillus fermentum attenuates the proinflammatory effect of Yersinia enterocolitica on human epithelial cells. Inflamm Bowel Dis 2007, 13:83-90.

44. Bernardeau M, Vernoux J, Gueguen M: Usefulness of epifluorescence for quantitative analysis of lactobacilli in probiotic feed. Appl Environ Microbiol 2001, 91:1103-1109.

45. Bernardeau M, Vernoux J, Henri-Dubernet S, Guéguen M: Safety assessment of dairy microorganisms: the Lactobacillus genus. Int J Food Microbiol 2008, 126:278-285.

46. Matte-Taillez O, Quénée P, Çibik R, Van Opstal J, Dessevre F, Firmesse O, Tailliez P: Detection and identification of lactic acid bacteria in milk and industrial starter culture with fluorescently labeled rRNA-targeted peptide nucleic acid probes. Lait 2001, 81:237-248.

47. Swidsinski A, Dorffel Y, Loening-Baucke V, Schilling J, Mendling W: Response of Gardnerella vaginalis biofilm to 5 days of moxi£oxacin treatment. FEMS Immunol Med Microbiol 2011, 61:41-46.

48. Munoa FJ, Pares R: Selective medium for isolation and enumeration of Bifidobacterium spp. Appl Environ Microbiol 1988, 54:1715-1718.

49. El Aila NA, Tency I, Saerens B, De Backer E, Cools P, dos Santos Santiago GL, Verstraelen $H$, Verhelst $R$, Temmerman $M$, Vaneechoutte M: Strong correspondence in bacterial loads between the vagina and rectum of pregnant women. Res Microbiol 2011, 162:506-513.

50. Gomes AMP, Malcata FX: Bifidobacterium spp. and Lactobacillus acidophilus: biological, biochemical, technological and therapeutical properties relevant for use as probiotics. Trends Food Sci. Technol 1999, 10:139-157.

51. Verstraelen $H$, Verhelst $R$, Vaneechoutte M, Temmerman M: Group A streptococcal vaginitis: an unrecognized cause of vaginal symptoms in adult women. Arch Gynecol Obstet 2011, 284:95-8.

52. Cerqueira L, Azevedo NF, Almeida C, Jardim T, Keevil C, Vieira MJ: DNA mimics for the rapid identification of microorganisms by fluorescence in situ hybridization (FISH). Int J Mol Sci 2008, 9:1944-1960.

53. Huys G, Vancanneyt M, D'Haene K, Falsen E, Wauters G, Vandamme P: Alloscardovia omnicolens gen. nov., sp. nov., from human clinical samples. Int J Syst Evol Microbiol 2007, 57:1442-1446.

54. Aroutcheva AA, Simoes JA, Behbakht K, Faro S: Gardnerella vaginalis isolated from patients with bacterial vaginosis and from patients with healthy vaginal ecosystems. Clin Infect Dis 2001, 33:1022-1027.

55. Briselden A, Hillier S: Longitudinal study of the biotypes of Gardnerella vaginalis. J Clin Microbiol 1990, 28:2761-2764.

56. Eren AM, Zozaya M, Taylor CM, Dowd SE, Martin DH, Ferris MJ: Exploring the diversity of Gardnerella vaginalis in the genitourinary tract microbiota of monogamous couples through subtle nucleotide variation. PLoS One 2011, 6:e26732-e26740.

57. Udayalaxmi J, Bhat GK, Kotigadde S: Biotypes and virulence factors of Gardnerella vaginalis isolated from cases of bacterial vaginosis. Indian J Med Microbiol 2011, 29:165-168.

58. Harwich MD, Alves JM, Buck GA, Strauss JF, Patterson JL, Oki AT, Girerd PH, Jefferson KK: Drawing the line between commensal and pathogenic Gardnerella vaginalis through genome analysis and virulence studies. BMC Genomics 2010, 11:375-386.

59. Witt A, Petricevic L, Kaufmann U, Gregor H, Kiss H: DNA hybridization test: rapid diagnostic tool for excluding bacterial vaginosis in pregnant women with symptoms suggestive of infection. J Clin Microbiol 2002, 40:3057-3059

60. Berlier JE, Rothe A, Buller G, Bradford J, Gray DR, Filanoski BJ, Telford WG, Yue S, Liu J, Cheung C, Chang W, Hirsch JD, Beechem JM, Haugland RP: Quantitative comparison of long-wavelength alexa fluor dyes to Cy dyes: fluorescence of the dyes and their bioconjugates. $J$ Histochem Cytochem 2003, 51:1699-1712.

doi:10.1186/1471-2180-13-82

Cite this article as: Machado et al:: Fluorescence in situ Hybridization method using Peptide Nucleic Acid probes for rapid detection of Lactobacillus and Gardnerella spp.. BMC Microbiology 2013 13:82. 